\title{
Sorafenib after Arterial Chemoembolization in Child-Pugh A and B Cirrhotic Patients with Intermediate Hepatocellular Carcinoma: A Retrospective Analysis
}

\author{
Fernando Gomes Romeiro1 ${ }^{*}$, Luciana Yumi Odani Sigahi', Matheus Alvarez ${ }^{3}$, \\ Fabio da Silva Yamashiro1, Fábio Cardoso de Carvalho', Leonardo Pelafsky ${ }^{4}$, \\ Talles Bazeia Lima1, Letícia de Campos Franzoni', José Ricardo de Arruda Miranda ${ }^{3}$, \\ Giovanni Faria Silva ${ }^{1}$ \\ ${ }^{1}$ Gastroenterology Division, Department of Internal Medicine, Faculdade de Medicina de Botucatu, \\ UNESP_Univ Estadual Paulista, São Paulo, Brazil \\ ${ }^{2}$ Faculdade de Medicina de Botucatu, UNESP_Univ Estadual Paulista, São Paulo, Brazil \\ ${ }^{3}$ Department of Physics and Biophysics, Instituto de Biociências de Botucatu, UNESP_Univ Estadual Paulista, \\ São Paulo, Brazil \\ ${ }^{4}$ Gastroenterology Division, Department of Surgery and Orthopedics, Faculdade de Medicina de Botucatu, \\ UNESP_Univ Estadual Paulista, São Paulo, Brazil \\ Email: fgromeiro@mb.unesp.br, luciana.sigahi@gmail.com, matheus@ibb.unesp.br, \\ fsyamashiro@fmb.unesp.br, fabioccarvalho@hotmail.com, Ipelafsky@yahoo.com.br, \\ tallesbazeialima@gmail.com, leticiafranzoni@hotmail.com, imiranda@ibb.unesp.br, giovanni@fmb.unesp.br
}

Received 9 February 2015; accepted 18 March 2015; published 19 March 2015

Copyright (C) 2015 by authors and Scientific Research Publishing Inc.

This work is licensed under the Creative Commons Attribution International License (CC BY).

http://creativecommons.org/licenses/by/4.0/

(c) (i) Open Access

\section{Abstract}

Introduction: Hepatocellular carcinoma (HCC) is a leading cause of mortality among cirrhotic patients, and current guidelines recommend single-treatment modalities according to patient and liver disease classifications. New studies have shown promising results from combining locoregional and systemic treatments, but most of them were limited to Child-Pugh A patients due to toxicity concerns. Aim: The objective of this study was to analyze survival rates of Child-Pugh A and B patients with intermediate HCC tumors treated with transarterial chemoembolization (TACE) followed by full-dose sorafenib usage. Material and methods: a retrospective analysis of 37 cirrhotic patients (Child-Pugh A and B rates $=23 / 14$ ) treated with TACE and TACE followed by sorafenib usage (17 and 20 patients, respectively). Results: The mean survival was 379 days in the combined treatment group and 151 days in the single-treatment group $(p=0.007)$. There were no differences in survival according to the Child-Pugh classification. Conclusions: sorafenib after TACE can be an option for selected cirrhotic patients with intermediate HCC tumors if this com-

\footnotetext{
*Corresponding author.
}

How to cite this paper: Romeiro, F.G., et al. (2015) Sorafenib after Arterial Chemoembolization in Child-Pugh A and B Cirrhotic Patients with Intermediate Hepatocellular Carcinoma: A Retrospective Analysis. Journal of Cancer Therapy, 6, $286-292$. http://dx.doi.org/10.4236/jct.2015.63031 
bined approach is cautiously performed on an individualized schedule. Our results suggest that the Child-Pugh classification should not be a limitation to this combined treatment.

\author{
Keywords
}

Hepatocellular Carcinoma, Cirrhosis, Arterial Chemoembolization, Sorafenib

\title{
1. Introduction
}

As the main histological tumor type originates in the liver, hepatocellular carcinoma (HCC) is found in $80 \%$ $90 \%$ of primary tumors of the organ [1] [2]. It is the fifth most common cancer worldwide and the third most common cause of cancer mortality after lung and stomach cancers [1] [3]. In the last two decades, the incidence of HCC in the USA increased $80 \%$ and the prevalence has been expected to rise due to the proliferation of chronic liver diseases such as chronic viral hepatitis B and C, alcohol abuse and hepatic steatosis [1]. Although the disease affects young people, the HCC prevalence is associated with age, which constitutes another reason to expect a high prevalence given the increasingly older worldwide population.

To choose the best treatment for each patient, it is essential to consider that most of them also have liver cirrhosis. Thus, the more aggressive treatments may also raise the risk of cirrhosis decompensation and death. On the other hand, the less aggressive treatments are still far from being able to provide a cure or tumor downstaging. Consequently, specific algorithms integrate the cirrhosis severity, the patient's functional status and the tumor characteristics.

Currently, the criteria to indicate the patient's allocation according to the best treatment options are the Barcelona Clinic Liver Cancer Staging Classification (BCLC), Cancer of the Liver Italian Program (CLIP), Japan Integrated Staging (JIS) and Okuda criteria. They combine the patient's functional capacity, tumor size, systemic and local tumor invasion, and hepatic function. The most widely used model is the BCLC [4], which provides the best stratification of prognosis for patients with HCC [5].

Nowadays there is consistent evidence on the efficacy of sorafenib, a multikinase inhibitor that targets angiogenesis in HCC, not only for prolonging the survival of patients but in some cases for allowing complete disease remission [6] [7]. Transarterial chemoembolization (TACE) and sorafenib are the current treatments for BCLC intermediate- and advanced-stage HCC, respectively. For these patients the initial locoregional treatment can be followed by systemic therapy; therefore, the recommendations according to the BCLC classification shall not be regarded as insurmountable barriers because sometimes the successive and/or more aggressive treatments allow increasing survival rates [8].

TACE procedures can cause hypoxia not limited to the tumor tissue but also in the surrounding liver parenchyma. Thus, the ischemic injury after TACE can induce the upregulation of circulating vascular endothelial growth factor (VEGF), leading to angiogenesis in the surrounding tumor. Based on this information, some studies started to combine sorafenib and TACE. Initial results seem encouraging, although there is a large heterogeneity of patients included in this type of combined treatment. One of the first randomized studies showed a longer time for the disease progression in patients with intermediate tumor stage [9]. Many other studies have been conducted worldwide, but when they are critically analyzed the authors have no doubts that more studies are needed to provide more reliable data about the indications of treatment combining TACE and sorafenib [10]-[12].

In this study we analyzed the survival of cirrhotic patients with intermediate tumor stage (BCLC staging B) treated by chemoembolization alone or followed by sorafenib. In both groups, patients had been treated in the University Hospital of Botucatu Medical School-UNESP.

\section{Materials and Methods}

This study was approved by the local Ethics Committee (protocol 485-2012) and carried out according to the Declaration of Helsinki and its revisions.

\section{Subjects}

A group of 37 cirrhotic patients (31 men and 6 women) were retrospectively selected to be included in the study. 
The inclusion criteria were a minimum age of 18 years, the diagnosis of HCC confirmed by the arteriography done before TACE and the diagnosis of cirrhosis based on clinical findings, liver biopsy or imaging exams (radiological or endoscopic findings compatible with cirrhosis and portal hypertension).

The exclusion criteria were previous solid-organ transplantation, other concomitant neoplastic disease, previous therapy with any other HCC treatment modalities, active alcohol abuse and incomplete TACE procedures (chemotherapeutic agent infusion without arterial embolization).

\section{Study Protocol}

The TACE procedures were accomplished by catheterization of the right femoral artery giving access to the aorta, common hepatic arteries and their branches until the vessels next to the tumor. The catheter was positioned into these vessels selectively in order to protect the remaining liver around the tumor. The chemotherapeutic agent doxorubicin was infused at the dose of $75 \mathrm{mg} / \mathrm{m}^{2}$ of body surface area, according to the total bilirubin levels:

Total bilirubin lower than $1.2 \mathrm{mg} / \mathrm{dl}=$ full dose

Total bilirubin between $1.2 \mathrm{mg} / \mathrm{dl}$ and $3 \mathrm{mg} / \mathrm{dl}=50 \%$ of the full dose

Total bilirubin between $3.1 \mathrm{mg} / \mathrm{dl}$ and $5 \mathrm{mg} / \mathrm{dl}=25 \%$ of the full dose

As soon as the doxorubicin was infused, the vessel embolization was performed with microspheres of 300 to $500 \mu \mathrm{m}$. The decision to initiate sorafenib (Nexavar, Bayer Health Care Pharmaceuticals, Inc., Wayne, NJ, USA) after TACE was defined by the doctors who conduct each patient treatment and not by the study protocol. Thus, the patients were allocated into two groups: one in which TACE was the only treatment and the other in which TACE was followed by sorafenib use.

All the subjects receiving the combined treatment were treated on an interrupted schedule: patients were placed on sorafenib in between TACE sessions, and sorafenib was not administered during TACE. The mean time between TACE and sorafenib introduction was 54 days ( 2 - 150 days, according to the medical staff decisions), and the drug was initiated in a full dose regimen (400 mg B.I.D.).

Survival analysis was performed according to the survival time between the TACE procedure and the date of death. For each patient relevant data were recorded, namely the age, Child-Pugh classification, MELD score, serum alpha-fetoprotein value, number of nodules, size of the largest tumor and number of TACE sessions.

The $t$ test was used for comparisons between continuous variables with normal distributions. The MannWhitney test was employed to compare the other variables. Survival data were plotted and survival rates were compared through log-rank test. All the statistical analysis was performed with the software Sigmastat version 3.5.

\section{Results}

In the sample evaluated, 20 patients had cirrhosis due to hepatitis $C, 5$ due to hepatitis $C$ concomitant with alcoholic liver disease, 3 on account of hepatitis B, 5 attributable to alcoholic liver disease and 4 had nonalcoholic fatty liver disease. All were initially treated through TACE in the Hemodynamics Unity of our Hospital.

Table 1 shows the data of all patients included in the study. Table 2 displays comparisons between patients treated exclusively with TACE and patients treated with TACE followed by sorafenib. Table 3 shows comparisons between Child-Pugh A and B patients.

The group treated exclusively with TACE and the group treated with TACE followed by sorafenib had no significant differences in relation to age, Child-Pugh classification, MELD score, number of tumors, largest tumor size, alpha-fetoprotein or current status at the end of the study.

However, the group receiving the combined treatment received the highest number of TACE sessions $(\mathrm{p}=$ 0.019 ) and had longer survival $(\mathrm{p}=0.002)$, as shown in Table 2 . The better survival was confirmed through the log-rank test as displayed in Figure 1.

There were no differences in survival according to Child-Pugh classification. The data indicate that Child-Pugh A patients were older and had lower MELD scores than Child-Pugh B patients, as shown in Table 3 .

\section{Discussion}

Despite our small sample size, the results showed that TACE associated with sorafenib led to a more favorable 
Table 1. Data from patients included in the study.

\begin{tabular}{ccccccccccc}
\hline & $\begin{array}{c}\text { Age } \\
\text { (years) }\end{array}$ & $\begin{array}{c}\text { Child-Pugh } \\
\text { (class) }\end{array}$ & $\begin{array}{c}\text { Child-Pugh } \\
\text { (points) }\end{array}$ & $\begin{array}{c}\text { MELD } \\
\text { score }\end{array}$ & $\begin{array}{c}\text { Number of } \\
\text { tumors }\end{array}$ & $\begin{array}{c}\text { Tumor size } \\
\text { (mm) }\end{array}$ & AFP (ng/ml) & $\begin{array}{c}\text { TACE } \\
\text { sessions }\end{array}$ & $\begin{array}{c}\text { Survival } \\
\text { (days) }\end{array}$ & $\begin{array}{c}\text { Current } \\
\text { status }\end{array}$ \\
\hline $\mathrm{Mi}$ & 30 & $22 \mathrm{~A}$ & 5 & 4.21 & 1 & 8 & 3.28 & 1 & 12 & $17 \mathrm{D}$ \\
$\mathrm{Q} 1$ & 52 & - & 5 & 8.86 & 1 & 45 & 25 & 1 & 150 & - \\
$\mathrm{M}$ & 58 & - & 6 & 10.54 & 2 & 52 & 80.49 & 1 & 266 & $6 \mathrm{LF}$ \\
$\mathrm{Q} 3$ & 64 & - & 7 & 12.64 & 2 & 63 & 793 & 2 & 472 & - \\
$\mathrm{Ma}$ & 88 & $15 \mathrm{~B}$ & 9 & 31.89 & 7 & 154 & 39800.00 & 4 & 1594 & $14 \mathrm{A \#}$ \\
\hline
\end{tabular}

AFP = alpha-fetoprotein; Child-Pugh = Child-Pugh classification; MELD score = Model of end-stage liver disease; Mi = minimum value; $\mathrm{Q} 1$ = first quartile; $\mathrm{M}=$ median; Q3 = third quartile; $\mathrm{Ma}=$ maximum value; $\mathrm{A}=$ Alive; $\mathrm{D}=$ Deceased; $\mathrm{LF}=$ loss of follow-up; \# = including 4 patients who achieved tumor down-staging and were submitted to liver transplantation.

Table 2. Comparisons between the groups according to treatments.

\begin{tabular}{|c|c|c|c|c|c|c|c|c|c|c|}
\hline & Age (years) & $\begin{array}{l}\text { Child-Pugh } \\
\text { (class) }\end{array}$ & $\begin{array}{l}\text { Child-Pugh } \\
\text { (points) }\end{array}$ & $\begin{array}{l}\text { MELD } \\
\text { score }\end{array}$ & $\begin{array}{l}\text { Number of } \\
\text { tumors }\end{array}$ & $\begin{array}{l}\text { Tumor size } \\
\text { (mm) }\end{array}$ & $\mathrm{AFP}(\mathrm{ng} / \mathrm{ml})$ & $\begin{array}{c}\text { TACE } \\
\text { sessions }\end{array}$ & $\begin{array}{l}\text { Survival } \\
\text { (days) }\end{array}$ & $\begin{array}{c}\text { Current } \\
\text { status }\end{array}$ \\
\hline Mi (T) & 30 & $10 \mathrm{~A}$ & 5 & 4.21 & 1 & 8 & 8.92 & 1 & 12 & $8 \mathrm{D}$ \\
\hline Q1 (T) & 50 & - & 6 & 9.65 & 1 & 45 & 48.86 & 1 & 77 & - \\
\hline$M(T)$ & 59 & - & 6 & 10.90 & 2 & 53 & 182.69 & 1 & 151 & $2 \mathrm{LF}$ \\
\hline Q3 (T) & 54 & - & 7 & 12.64 & 2 & 62 & 1647.11 & 1 & 293 & - \\
\hline Мa (T) & 88 & $7 \mathrm{~B}$ & 9 & 17.80 & 3 & 72 & 39800.00 & 2 & 1020 & $5 \mathrm{~A} \#$ \\
\hline Mi (TS) & 49 & $13 \mathrm{~A}$ & 5 & 5.85 & 1 & 29 & 3.28 & 1 & 105 & 9D \\
\hline Q1 (TS) & 53 & - & 5 & 8.36 & 1 & 46 & 6.66 & 1 & 201 & - \\
\hline M (TS) & 58 & - & 5 & 10.37 & 2 & 51 & 38.76 & 1.5 & 362 & $4 \mathrm{LF}$ \\
\hline Q3 (TS) & 64 & - & 7 & 12.56 & 2 & 70 & 172.25 & 3 & 932 & - \\
\hline Мa (TS) & 73 & $7 \mathrm{~B}$ & 9 & 31.89 & 7 & 154 & 5845.00 & 4 & 1594 & 7A\#\# \\
\hline $\mathrm{p}$ & 0.975 & 0.717 & 0.071 & 0.681 & 0.909 & 0.176 & 0.051 & $0.019^{*}$ & $0.002^{*}$ & 0.717 \\
\hline
\end{tabular}

AFP = alpha-fetoprotein; Child-Pugh = Child-Pugh classification; MELD = Model of end-stage liver disease; TACE = transarterial chemoembolization; $\mathrm{Mi}=$ minimum value; $\mathrm{Q} 1$ = first quartile; $\mathrm{M}=$ median; $\mathrm{Q} 3=$ third quartile; $\mathrm{Ma}=$ maximum value; $\mathrm{A}=\mathrm{Alive}$; $\mathrm{D}=\mathrm{Deceased}$; $\mathrm{LF}=$ loss of follow-up; $(\mathrm{T})$ = data from patients who were treated only with TACE; $(\mathrm{TS})$ = data from patients who received the combined treatment; \# = including 1 patient who achieved tumor down-staging and was submitted to liver transplantation; \#\# = including 3 patients who achieved tumor down-staging and were submitted to liver transplantation; $\mathrm{p}=\mathrm{p}$ value. ${ }^{*}=$ significant differences between TACE and TACE-plus-sorafenib groups. Age, tumor size and survival were compared using $t$ test. The other variables were compared via the Mann-Whitney test.

prognosis than TACE alone. Other studies have already shown a similar increase in the survival rate of patients treated with sorafenib after TACE, hypothesizing that the prolonged survival would be achieved in these patients because sorafenib can control VEGF levels, which increase after TACE [12].

First, considering only the TACE risks, a retrospective study evaluating the TACE-related risks in patients with hepatic dysfunction performed by Garwood et al. found that reversible and irreversible hepatotoxicity was developed in $31 \%$ and $15 \%$ of patients, respectively. Forty percent of patients presented Child-Pugh B and their MELD score was $13 \pm 4$ (in our study it was $11.5 \pm 5$ ). The median survival time was 10.3 months (309 days) from the date of the first TACE, while in our sample the mean and the median were 420 and 266 days, respectively. Among the subjects not submitted to liver transplantation, the average survival was 8 months (240 days) [13]. These values were similar to those found in our study, in which only four patients $(10.8 \%$ of the total sample) were submitted to liver transplantation after achieving tumor down-staging.

Since we had fourteen Child-Pugh B patients receiving both treatments, the first concern in our study was the survival rates. In a retrospective study on HCC treatment in Child-Pugh B patients, Piscaglia et al. have eva- 


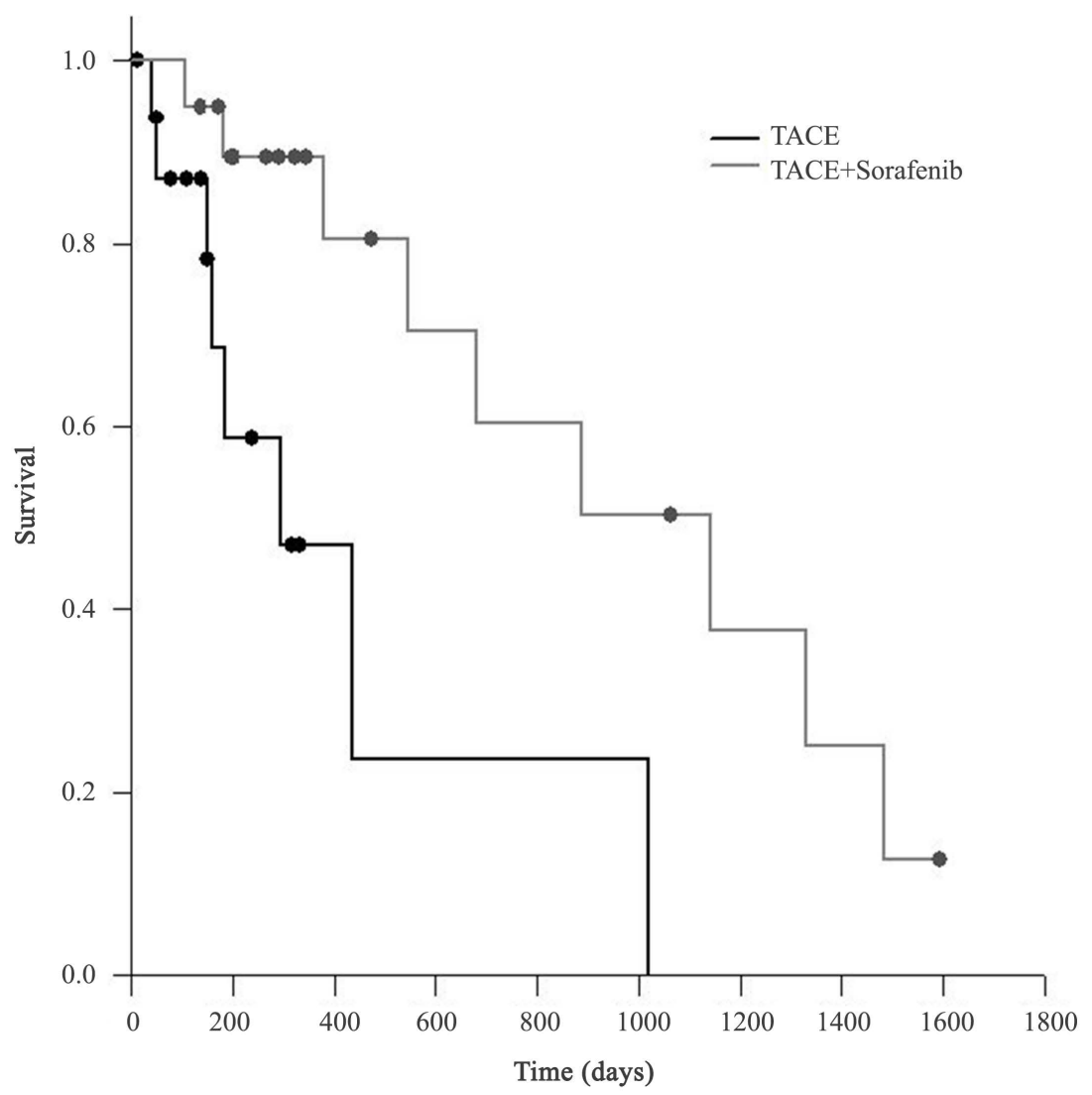

Figure 1. Survival time of the two study groups (log-rank test). TACE = transarterial chemoembolization. The group treated with TACE followed by sorafenib is represented in gray and the group treated only with TACE is shown in black. Kaplan-Meier survival was higher in the group that received the combined treatment $(p=0.007)$.

Table 3. Comparisons between the patients according to Child-Pugh classification.

\begin{tabular}{cccccccccc}
\hline & Age (years) & $\begin{array}{c}\text { Child-Pugh } \\
\text { (points) }\end{array}$ & MELD score & $\begin{array}{c}\text { Number of } \\
\text { tumors }\end{array}$ & $\begin{array}{c}\text { Tumor size } \\
(\mathrm{mm})\end{array}$ & AFP (ng/ml) & TACE sessions & $\begin{array}{c}\text { Survival } \\
\text { (days) }\end{array}$ & $\begin{array}{c}\text { Current status } \\
\text { Mi (A) }\end{array}$ \\
\hline & 46 & 5 & 4.21 & 1 & 8.00 & 3.28 & 1 & 40 & $9 \mathrm{D}$ \\
Q1 (A) & 56 & 5 & 8.00 & 1 & 45.00 & 8.00 & 1 & 144 & - \\
M (A) & 60 & 5 & 9.19 & 2 & 50.00 & 79.08 & 1 & 196 & $4 \mathrm{LF}$ \\
Q3 (A) & 67 & 6 & 10.61 & 2 & 66.00 & 571.50 & 2 & 454 & - \\
Ma (A) & 88 & 6 & 12.64 & 3 & 154.00 & 5845.00 & 4 & 1482 & $10 \mathrm{A \#}$ \\
Mi (B) & 30 & 7 & 9.65 & 1 & 29.00 & 6.81 & 1 & 12 & $8 \mathrm{D}$ \\
Q1 (B) & 50 & 7 & 12.00 & 1 & 46.00 & 33.00 & 1 & 170 & - \\
M (B) & 52 & 8 & 14.41 & 1 & 52.50 & 108.54 & 1 & 319 & $2 \mathrm{LF}$ \\
Q3 (B) & 61 & 8 & 17.22 & 1 & 59.50 & 1319.08 & 1 & 504 & - \\
Ma (B) & 65 & 9 & 31.89 & 3 & 73.00 & 39800.00 & 3 & 1594 & $4 \mathrm{A \#}$ \\
P & 0.011 & $<0.001^{*}$ & $<0.001^{*}$ & 0.700 & 0.975 & 0.287 & 0.216 & 0.627 & 0.381 \\
\hline
\end{tabular}

AFP = alpha-fetoprotein; Child-Pugh = Child-Pugh classification; MELD = Model of end-stage liver disease; TACE = transarterial chemoembolization; $\mathrm{Mi}=$ minimum value; $\mathrm{Q} 1$ = first quartile; $\mathrm{M}=$ median; $\mathrm{Q} 3$ = third quartile; $\mathrm{Ma}=$ maximum value; $\mathrm{A}=\mathrm{Alive}$; $\mathrm{D}=\mathrm{Deceased}$; LF = loss of follow-up; (A) = data from Child-Pugh A patients; (B) = data from Child-Pugh B patients; \# = including 2 patients in each Child-Pugh classification who achieved tumor down-staging and were submitted to liver transplantation; ${ }^{*}=$ significant differences between Child-Pugh A and B groups. Age and MELD scores were compared using $t$ test. The other variables were compared via the Mann-Whitney test. 
luated 27 patients with intermediate stage tumors. The median survival was 8.0 months (9.0 in Child-Pugh B7 vs. 6.0 in Child-Pugh B8/B9). Respective survival times of patients with Child-Pugh B7 and B8 with intermediate stage tumors who underwent TACE were 22.0 and 6.0 months [14]. As our sample had 14 Child-Pugh B patients (two B9, six B8 and six B7), we had expected similar results.

There are few studies combining TACE and sorafenib that include Child-Pugh B patients to compare the results with our findings, because most of these trials comprised only Child-Pugh A patients. In the study of Sansonno et al. there was a longer time until disease progression in cirrhotic patients with hepatitis $\mathrm{C}$ and intermediate-stage HCC tumors treated with sorafenib starting 30 days after TACE [9]. Although in our sample most patients also presented hepatitis C-related cirrhosis, we had $40.54 \%$ of patients with Child-Pugh B whereas the trial of Sansonno et al. was limited to Child-Pugh A patients. Other differences are the mean alpha-fetoprotein in our sample (1925.86 ng/ml, which was more than 10 times higher than in this previous study), and the fact that most of our patients had more than one tumor; thus, the reasons for a lower survival rate were clear. However, since our patients had worse liver diseases, the question was whether they would receive less benefit from sorafenib use after TACE.

This concern increased when we found a recent trial that was apparently similar to our study in which Sieghart et al. included 12 Child-Pugh A and 3 Child-Pugh B patients receiving their first TACE session two weeks after initiating sorafenib usage. Two other TACE sessions were planned in monthly intervals. These patients had BCLC classification $\mathrm{A} / \mathrm{B} / \mathrm{C}=1 / 9 / 5$, indicating that although most of them have compensated cirrhosis, some patients already had advanced tumors. This study was prematurely stopped because of safety concerns. At 6 months, seven patients presented complete (two) or partial (five) responses, and one had stable disease. Median overall survival was 10.6 months (95\% CI: 5.2 - 16 months) [15].

Compared to this latter survival rate, the better result obtained in our study (despite our bigger proportion of Child-Pugh B patients) cannot be explained only by the 5 advanced HCC cases included in this previous trial. In our opinion, the more aggressive design in the trial of Sieghart et al. could be the key issue. In our study, the patients had time to recover between TACE and the sorafenib introduction, and the decision of repeating TACE sessions was taken by the medical staff and the patients, allowing a more flexible schedule. In the study of Sieghart et al., the first TACE session was performed two weeks after the patients had initiated the sorafenib treatment, and the subsequent sessions were planned to be carried out without interrupting the systemic treatment. Even so, other studies are needed to confirm our hypotheses.

\section{Conclusion}

In conclusion, our study suggests that the combined treatment with TACE and sorafenib is feasible in patients with intermediate HCC tumors. Furthermore, our data suggest that this treatment could be an option for ChildPugh B patients on an interrupted schedule, in order to achieve survival rates similar to those of Child-Pugh A patients. This combination should be individualized and carefully planned; and it seems important to avoid the concomitant locoregional and systemic treatments in Child-Pugh B patients.

\section{Acknowledgements}

The authors wish to thank FAPESP (grant 2013/17361-6, São Paulo Research Foundation—FAPESP) and UNESP for supporting our research.

\section{Competing Interests}

The authors declare that they have no competing interests.

\section{Disclaimer}

Bayer gave unrestrictive grant/funding support to publish it without influencing on the content or so.

\section{Authors' Contributions}

FGR designed the study, conducted the patients, obtained the data, performed the data analysis, drafted and corrected the final article. LYS organized all the patients' data, participated in the data analysis and drafted the ar- 
ticle. MA and JRAM participated in the data analysis, drafted and corrected the final article. FSY, LCF, LP and TBL conducted the patients and obtained the data. FCC performed all the TACE procedures. GFS conducted the patients, participated in the data analysis, and drafted and corrected the article. All authors read and approved the final manuscript.

\section{References}

[1] Gomaa, A.I., Khan, S.A., Tolledano, M.B., Waked, I. and Taylor-Robinson, S.D. (2008) Hepatocellular Carcinoma: Epidemiology, Risk Factors and Pathogenesis. World Journal of Gastroenterology, 14, 4300-4308. http://dx.doi.org/10.3748/wjg.14.4300

[2] Lau, W.T. and Lai, E.C.H. (2008) Hepatocellular Carcinoma: Current Management and Recent Advances. Hepatobiliary \& Pancreatic Diseases International, 7, 237-257.

[3] Ferlay, J., Shin, H.R., Bray, F., Forman, D., Mathers, C. and Parkin, D.M. (2010) Estimates of Worldwide Burden of Cancer in 2008: GLOBOCAN 2008. International Journal of Cancer, 127, 2893-2917. http://dx.doi.org/10.1002/ijc.25516

[4] Bruix, J., Sherman, M., Llovet, J.M., Beaugrand, M., Lencioni, R., Burroughs, A.K., et al. (2001) Clinical Managementof Hepatocellular Carcinoma: Conclusions of the Barcelona-2000 EASL Conference. Journal of Hepatology, 35, 421-430. http://dx.doi.org/10.1016/S0168-8278(01)00130-1

[5] Gomaa, A.I., Hashim, M.S. and Waked, I. (2014) Comparing Staging Systems for Predicting Prognosis and Survival in Patients with Hepatocellular Carcinoma in Egypt. PLoS One, 9, e90929. http://dx.doi.org/10.1371/journal.pone.0090929

[6] Bruix, J., Raoul, J.L., Sherman, M., Mazzaferro, V., Bolondi, L., Craxi, A., Galle, P.R., Santoro, A., Beaugrand, M., Sangiovanni, A., Porta, C., Gerken, G., Marrero, J.A., Nadel, A., Shan, M., Moscovici, M., Voliotis, D. and Llovet, J.M. (2012) Efficacy and Safety of Sorafenib in Patients with Advanced Hepatocellular Carcinoma: Subanalyses of a Phase III Trial. Journal of Hepatology, 57, 821-829. http://dx.doi.org/10.1016/j.jhep.2012.06.014

[7] Kudo, M. and Ueshima, K. (2010) Positioning of a Molecular-Targeted Agent, Sorafenib, in the Treatment Algorithm for Hepatocellular Carcinoma and Implication of Many Complete Remission Cases in Japan. Oncology, 78(S1), 154166. http://dx.doi.org/10.1159/000315245

[8] Radu, P., Groza, I., Iancu, C., Al Hajjar, N., Andreica, V. and Sparchez, Z. (2013) Treatment of Hepatocellular Carcinoma in a Tertiary Romanian Center. Deviations from BCLC Recommendations and Influence on Survival Rate. Journal of Gastrointestinal and Liver Diseases, 22, 291-297.

[9] Sansonno, D., Lauletta, G., Russi, S., Conteduca, V., Sansonno, L. and Dammacco, F. (2012) Transarterial Chemoembolization Plus Sorafenib: A Sequential Therapeutic Scheme for HCV-Related Intermediate-Stage Hepatocellular Carcinoma: A Randomized Clinical Trial. The Oncologist, 17, 359-366. http://dx.doi.org/10.1634/theoncologist.2011-0313

[10] Liapi, E. and Geschwind, J.F. (2012) Combination of Local Transcatheter Arterial Chemoembolization and Systemic Antiangiogenic Therapy for Unresectable Hepatocellular Carcinoma. Liver Cancer, 1, 201-215. http://dx.doi.org/10.1159/000343835

[11] Weintraub, J.L. and Salem, R. (2013) Treatment of Hepatocellular Carcinoma Combining Sorafenib and Transarterial Locoregional Therapy: State of the Science. Journal of Vascular and Interventional Radiology, 24, 1123-1134. http://dx.doi.org/10.1016/j.jvir.2013.01.494

[12] Kim, H.Y. and Park, J.W. (2014) Clinical Trials of Combined Molecular Targeted Therapy and Locoregional Therapy in Hepatocellular Carcinoma: Past, Present, and Future. Liver Cancer, 3, 9-17. http://dx.doi.org/10.1159/000343854

[13] Garwood, E., Fidelman, N., Hoch, S.E., Kerlan Jr., R.K. and Yao, F.Y. (2013) Morbidity and Mortality Following Transarterial Liver Chemoembolization in Patients With Hepatocellular Carcinoma and Synthetic Hepatic Dysfunction. Liver Transplantation, 19, 164-173. http://dx.doi.org/10.1002/lt.23552

[14] Piscaglia, F., Terzi, E., Cucchetti, A., Trimarchi, C., Granito, A., Leoni, S., Marinelli, S., Pini, P. and Bolondi, L. (2013) Treatment of Hepatocellular Carcinoma in Child-Pugh B Patients. Digestive and Liver Disease, 45, 852-858. http://dx.doi.org/10.1016/j.dld.2013.03.002

[15] Sieghart, W., Pinter, M., Reisegger, M., Müller, C., Ba-Ssalamah, A., Lammer, J. and Peck-Radosavljevic, M. (2012) Conventional Transarterial Chemoembolisation in Combination with Sorafenib for Patients with Hepatocellular Carcinoma: A Pilot Study. European Radiology, 22, 1214-1223. http://dx.doi.org/10.1007/s00330-011-2368-z 